\title{
Impacts of Synthetic and Botanical Pesticides on Beneficial Insects
}

\author{
Baltazar Ndakidemi, Kelvin Mtei, Patrick A. Ndakidemi \\ Department of Water and Environmental Sciences (WESE), The Nelson Mandela African Institution of Science \\ and Technology, Arusha, Tanzania \\ Email: ndakidemib@nm-aist.ac.tz
}

Received 7 March 2016; accepted 14 June 2016; published 17 June 2016

Copyright @ 2016 by authors and Scientific Research Publishing Inc.

This work is licensed under the Creative Commons Attribution International License (CC BY). http://creativecommons.org/licenses/by/4.0/

c) (i) Open Access

\begin{abstract}
Sustainable methods to control insect pests that affect crop yield have become a great challenge to mainly smallholder farmers. Beneficial insects in agricultural fields play an important role in natural pest control and pollination. The use of synthetic and botanical pesticides has detrimental effects to both natural enemies and pollinators in agricultural fields. The pesticides affect the survival of a range of life cycle stages, reductions in reproductive capacity, changes in the suitability of hosts for parasitising or predation, reduced emergence of parasitoids from sprayed host eggs and cause direct mortality. This has caused a serious menace to biological control agents and pollinators. When natural enemies are reduced, even more serious consequences may result for pest population dynamics which include the phenomena of resurgence and eruption of secondary pests. The decrease in pollinators reduces agricultural productivity. This review aims at exploring the side effects of synthetic and botanical pesticides on beneficial insects to give the basis for research on the negative impacts of synthetic and botanical pesticides on these insects. This information will assist in optimizing the use of pesticides in integrated pest management programmes by employing more sustainable and ecosystem benign practices such as the use of right dosage and selective pesticides in agricultural fields.
\end{abstract}

\section{Keywords}

Biological Control, Pollinators, Predators, Parasitoids, Ecosystem

\section{Introduction}

In agricultural/ecological context, insects can be grouped into beneficial or non-beneficial (pests). The beneficial insects in agriculture include pollinators as well predators and parasites of pest insects (parasitoids). They 
provide natural ecosystem services such as biological control of crop pests and pollination of crops. In recent times, modern agriculture has brought the use of herbicides and pesticides due to occurrences of pests and diseases [1]. In doing so, the activities of beneficial insects can be disrupted when pesticides are used in agricultural fields as the abundance and species composition of these beneficial insects will be affected [2]. Most available field crop synthetic insecticides have broad spectrum activity which kill both beneficial insects and pests. Broad-spectrum synthetic insecticides include the organochlorines, organophosphates, carbamates and pyrethroids. These have been widely used since their introduction in the 1940s and 1950s [3]. Organophosphates are some of the most insect-toxic pesticides which with carbamates and pyrethroids are nerve poisons [4]. Organophosphates and carbamates are specifically cholinesterase inhibitors while pyrethroids specifically are sodium channel modulators which overexcite neurons. Organophosphates include acephate, chlorpyrifos, malathion and phosmet while pyrethroids are cyfluthrin, esfenvalerate, $\lambda$-cyhalothrin and permethrin. Cabamates include aldicarb and carbaryl which cause negative impacts on insects' survival, growth, development, reproduction (sexual ratio, fecundity, longevity and fertility), and behaviour (motility, orientation, feeding, oviposition and learning) [4].

Some plant-derived and synthetic pesticides have negative impacts on natural enemies and pollinators. [5] reported that basically, pesticidal plants have the active ingredients similar to synthetic pesticides and therefore, they can cause the negative impacts to non-target natural enemies and pollinators. A decline in the wild pollinators, for instance, has been documented in many regions of the globe. One of the causes for the decline is the pesticide use which causes direct and indirect adverse effects on beneficial insects' populations [6]. Some botanicals are non-specific and toxic. Nicotine from tobacco plant extract, for instance, is classified as WHO Class Ib which means highly hazardous. Rotenone from Derris and Tephrosia species is classified as Class II. Rotenone and natural pyrethrum from chrysanthemum are highly toxic [7]. Synthetic pesticides also when applied kill other non-targeted organisms such as natural predators and parasites of the pests and organisms that are beneficial to health and balance of the ecosystem [8]. Pesticides poisoning can cause population declines and, therefore, threaten the rare species by causing abnormal behavioural changes [9]. In Africa, the extent of pesticides' use is very low compared with the global market and it has recently been recorded that Sub Saharan Africa is about $2 \%$ relatively lower than other African countries [10].

There is limited understanding of the impacts of botanical and synthetic pesticides on natural enemies and pollinators in most of sub-Saharan Africa. This poses a need to generate information on impacts of botanical pesticides as well as synthetic products on beneficial insects especially the natural enemies and pollinators in agricultural fields. This review aims at documenting the impacts of synthetic and botanical pesticides on beneficial insects. This will provide the basis for research on the side effects of synthetic and botanical pesticides and consequently develop practices that will help to prevent these effects on non-targeted beneficial insects.

\section{Effects of Synthetic Pesticides Use on Beneficial Insects}

\subsection{Lethal Effects (Direct Effects)}

Synthetic pesticides can cause lethal effects to beneficial insects and the main lethal effect is the direct killing. Predators and parasitoids tend to be more susceptible to pesticides than plant-feeding insects because, plant feeding insects may possess detoxification mechanisms produced by plants [11]. Pesticides kill natural enemies including those in resistant stages at the time of application and those which will migrate into the sprayed area. There is also possibilities of accumulation of the pesticides to lethal levels if the pesticides do not kill the exposed natural enemies immediately at the time of application [12]. The parasite larva that lives inside the host will not develop if the host is killed by the pesticide [12]. [13] reported on the lethal effects of the insecticides cartap, imidacloprid, malathion, metamidophos, acephate, acetamiprid and abamectin. These pesticides caused more than $61 \%$ of mortality of the parasitoid Encarsia sp. It has been further been reported by [13] that the pesticides cartap, imidacloprid, malathion, metamidophos, acephate, acetamiprid and abamectin increased mortality of the emerged parasites. [14] reported on the side effects of five pesticides namely Profect (w.p.), CAPL-2 (mineral oil), Lambda-cyhalothrin, Spinosad and Fenitrothion (Sumithon) on the immature stages of the parasitoid wasp Trichogramma evanescens. The pesticides caused mortality of the emerged adults within few hours post emergence. [13] further reported that higher concentrations of Sulphur pesticide in agricultural fields increased mortality of adult parasitoid wasp Trichogramma and reduced the fitness of the emerged wasps. 
[15] carried out an experiment to evaluate the effects of some insecticides on the abundance and mortality of predacious Ladybird beetle in bean ecosystem. He revealed the highest number of dead Ladybird beetle after treatment with Curtap 50 SP @ 2 g/L water (4.45), followed by Esfenvalerate 5 EC @ 1 ml/L water (4.29), Deltrametrin 2.5 EC @ 1 ml/L water (3.96), Cypermethrin 10 EC @ 1 ml/L water (3.62) and Fenitrothion 50 EC @ $1 \mathrm{ml} / \mathrm{L}$ water (3.29), Fenvelarate 20 EC @ 1 ml/L water (2.70) and Emamectin benzoate 5 SG @ 1 g/L water (2.97). In the study conducted by [16] on effects of Diazinon and Nogos @ 2 ml/L water on Ladybird beetles larva and adults, the pesticides caused $86.7 \%$ and $83.3 \%$ larval mortality and $86.7 \%$ and $93.3 \%$ adult mortality respectively.

The study conducted by [17] on the lethal and behavioral effects of pesticides on the insect predator Macrolophus pygmaeus (Hemiptera: Miridae), thiacloprid pesticides caused 100\% mortality to M. pygmaeus nymphs. [18] further reported on the mortality of foraging predators and parasitoids when they were subjected to the application of imidacloprid on foliage.

[19] found that imidacloprid in the nectar of flowers is the result of the imidacloprid applied as soil granular and thereafter translocated to flowers; consequently caused mortality of parasite of mealybug (Anagyrus pseudococci). The mortality occurred due to hyperexcitation, convulsions and paralysis caused by imidacloprid overstimulation of the synapses [20]. Greater understanding of the lethal effects of synthetic pesticides on beneficial insects will contribute significantly in avoiding lethal pesticides and consequently promoting the beneficial insects' populations.

\subsection{Non-Lethal Effects (Indirect Effects)}

Non-lethal effects of pesticides include weakening of the insects (predators and parasitoids), changing their behaviour and lengthening the development period of the immature stages which will lead to the reduced prey consumption and reproductive ability [21]. Other indirect effects are as follows.

\subsubsection{Reduced Ability to Capture Prey}

[22] found that doses of cypermethrin reduced predators' capacity of finding and capturing prey. The study further reported that parasitoids submitted to insecticides lambdacyhalothrin and carbamates treatments reduced their capacity of guiding themselves to the host plants with aphids attack. When treated with fenvalerate and methomyl, females of Microplitis croceipes (Braconidae) which is a parasitoid of Heliothis sp. (Lepidoptera: Noctuidae) reduced flying activity 20 hours after the treatment [23]. Mechanisms through which the synthetic pesticides reduce the ability of predators from capturing prey need to be studied to give the basis of optimizing the future use of selective synthetic pesticides.

\subsubsection{Reduced Food Resources for Predators, Parasitoids and Pollinators}

Pesticides can have indirect effects by decreasing plants and insects which are food sources to other beneficial insects. Herbicides can change the habitats by altering vegetation structure ultimately leading to the decline of beneficial insects' populations. They can suppress plants which are used to provide nectar, pollen and honeydew to natural enemies and also eliminate the non-pests species that serve as alternative source of food for natural enemies and which provide favourable conditions for their survival. The elimination of the hosts or prey for instance by pesticidal effects will lead to the natural enemies lack food resources and therefore these natural enemies will have to leave in search of alternative prey or host. Thus, there will be no natural enemies to suppress the activities of pests [24]. Dosage of imidacloprid above 20 ppb has been reported by [25] to reduce the ability of bumble bees and honey bees to step into food sources. There is limited knowledge on the types of synthetic pesticides that reduce the food resources for beneficial insects and therefore exploring these pesticides would help in conserving predators, parasitoids and pollinators.

\subsubsection{Oviposition and Feeding Repellency of Predators and Parasitoids}

Some inorganic insecticides present on foliage may bring physical irritation to predators and parasitoids especially the small ones. Insecticides may cause repellency for feeding and oviposition. The insects will rarely oviposit on plants sprayed by pesticides [2]. Insecticides may cause physiological changes by affecting the nervous and hormonal balance of beneficial insects. The natural enemies may reduce the probability of finding their hosts for oviposition because of the indirect disturbance caused by the repellent effect of insecticides [26]. 
Better understanding of the repellency effects of the synthetic pesticides and how they cause changes in beneficial insects' physiology will promote their populations in agricultural fields.

\subsubsection{Developmental Impairment of Parasitoids and Predators}

[27] did a laboratory experiment (using the IOBC classification) to investigate the effects of insecticide amitraz on the parasitoid wasp, Encarsia formosa used to control the whitefly, Trialeurodes vaporariorum. It was observed that amitraz at the maximum recommended field concentration $(E=89.09)$ and $1 / 2$ dose $(E=82.3)$ were harmful and $1 / 4$ dose $(E=63.2)$ was moderately harmful to $E$. formosa.

[28] found out that, mancozeb was toxic to predatory mites of the family Phytoseiidae and therefore, discouraging its use will encourage populations of the phytoseiid mites, which are able to greatly control the two spotted spider mite in the absence of the chemical. The insecticide fenoxycarb was reported to cause the prolonged time of development of the predator Chysoperla rufilabris (Neuroptera: Chrysopidae) in all the stages as reported by [29].

[30] discovered destruction of the scelionid egg parasitoid Trissolcus grandis (Hymenoptera: Scelionidae) which had been used in the control of Eurygaster integriceps populations due to intensive use of insecticides. Effects of the insecticides Fenitrothion and deltamethrin on adults and preimaginal stages of egg parasitoid Trissolcus grandis have been also reported by [31]. The insecticides significantly reduced the emergence rates by $18.0 \%$ and $34.4 \%$, respectively, compared with the control. In the study by [32] on the effects of dimethoate, spinosad, imidacloprid and pirimicarb on the survival and longevity of Aphidius ervi, an important parasitoid of the pea aphid, (Acyrthosiphon pisum), it was unveiled that after 24 hours, dimethoate had caused total mortality of all Aphidius ervi adults subjected to the treatment, followed by pirimicarb and the last one being spinosad (Table 1).

The developmental impairment caused by synthetic pesticides have great impacts on biological control of agricultural pests. There is therefore a need of studying the dynamics of the predatory and parasitic activities affected by these developmental anomalies.

\subsubsection{Reduced the Foraging Ability of Pollinators}

[33] studied foraging behavior of honey bees (Apis millifera) and reported the abnormal foraging when the honey bees were subjected to the pesticide imidacloprid and they could not return to the feeding site in the same way as untreated bees did. [19] reported that bees lost navigation and foraging skills when subjected to sub lethal doses of neonicotinyl insecticide. [34] showed that when the honey bees were subjected to doses of imidacloprid above $30 \mathrm{ppb}$, the foraging rates slowed down and handling time increased.

Further research on the reduced foraging ability of both the pollinators and natural enemies of pests caused by synthetic pesticides is the way forward towards preserving the bees hence, promoting biological control and pollination in agriculture.

\subsubsection{Reproductive Impairment of Predators and Parasitoids}

[35] reported sub-lethal effects of the insecticide Spinosad which accumulated in the ovaries of the parasitoid, Hyposoter didymator. It also reduced the rate of fecundity and size of this insect. When submitted to low doses of the insecticide deltamethrin, the males of Thrichogramma brassicae did not respond to the signals of females, while treated females reduced the capacity of attracting untreated males [35]. Wettable sulfur which is effective against mites and thrips and hydrated lime which is effective against leafhoppers can cause infertility which may

Table 1. Adults of Aphidius ervi surviving after 24 hours' exposure to insecticides at sub-lethal concentrations.

\begin{tabular}{ccccc}
\hline Treatments & Surviving adults & Males & Females & Average \\
Dimethoate & $0.00 \pm 0.00 \mathrm{a}$ & $0.00 \pm 0.00 \mathrm{a}$ & $0.00 \pm 0.00 \mathrm{a}$ & $0.00 \pm 0.00 \mathrm{a}$ \\
Spinosad & $23.00 \pm 0.00 \mathrm{c}$ & $6.89 \pm 0.15 \mathrm{~b}$ & $6.40 \pm 0.29 \mathrm{c}$ & $6.78 \pm 0.05 \mathrm{c}$ \\
Imidacloprid & $22.00 \pm 0.41 \mathrm{~b}$ & $8.70 \pm 0.30 \mathrm{c}$ & $8.10 \pm 0.24 \mathrm{~d}$ & $8.47 \pm 0.22 \mathrm{~d}$ \\
Pirimicarb & $22.75 \pm 0.25 \mathrm{c}$ & $6.64 \pm 0.19 \mathrm{~b}$ & $5.15 \pm 0.54 \mathrm{~b}$ & $6.31 \pm 0.16 \mathrm{~b}$ \\
Control & $23.00 \pm 0.00 \mathrm{c}$ & $9.95 \pm 0.19 \mathrm{~d}$ & $8.55 \pm 0.38 \mathrm{~d}$ \\
\hline
\end{tabular}

Modified from [32]. 
be one of the main factors for the reduction of arthropod longevity. Infertility in adults may also influence the dynamics of populations as matting does not generate fertile eggs [36]. When parasitoid Trichogramma pretiosum was subjected to insecticide organophosphate chlorpyrifos, it reduced the number of females [22]. The parasitoid T. pretiosum presented variation in sexual ratios when subjected to the insecticides. Due to chemical consumption, females may suffer from ovary deformations and this has impacts on sexual ratios [37]. [38] reported the effects of the spinosad on adult longevity and fecundity of the common green lacewing, Chrysoperla carnea. The insecticide fenoxycarb has been reported to cause the prolonged time of development of the predator Chysoperla rufilabris in all the stages [29]. Investigations of different synthetic pesticides that cause reproductive impairment to predators, parasitoids and pollinators could enhance the host-finding and pollination efficiency. Also more knowledge on non-lethal effects of the synthetic pesticides on natural enemies, parasitoids and pollinators is important in increasing their efficiency to control pests and pollinating the crops in agricultural fields.

\section{Impacts of Botanical Pesticides on Beneficial Insects}

\subsection{Lethal Effects (Direct Effects)}

Several botanical pesticides have caused mortality to beneficial insects due to their toxicity. These include among others citronella, eucalyptus, garlic, pyrethrum and neem products [39].

[40] reported on very high mortalities of Venturia canescens for the $\mathrm{LC}_{25}$ value of pyrethrum. At the $\mathrm{LC}_{50}$, pyrethrum was highly toxic to $V$. canescens and caused $100 \%$ mortality. $100 \%$ mortality of egg-larval parasitoid Chelonus oculator (Braconidae) occured when subjected to the $\mathrm{LC}_{50}$ value of pyrethrum as reported by [41]. When larvae of Ephestia kuehniella as parasitoid hosts were treated at $\mathrm{LC}_{50}$ and $\mathrm{LC}_{25}$ values of Azadirachtin, very few adult parasitoids emerged which indicated a strong detrimental effect on the parasitoid. [42] reported on effects of botanical insecticides naphthoquinones from the Chilean plant Calceolaria andina L. (Scrophulariaceae), and derivatives from Azadirachta indica and pyrethrum products on the behaviour and mortality of whitefly Trialeurodes vaporariorum and the parasitoid Encarsia formosa, at lower concentrations, pyrethrum caused mortality to both the adults of Trialeurodes vaporariorum and its parasite Encarsia formosa.

Moreover, [15] found that the mortality of lady beetles in bean fields when treated with Neem oil (fresh) @ $2.5 \mathrm{ml} / \mathrm{L}$ water, Neem oil (stored) @ $2.5 \mathrm{ml} / \mathrm{L}$ water. Rotenone and neem reduced the numbers of adult anthocorid Orius laevigatus, a predator of flower thrips, Frankliniella occidentalis [43]. [44] reported that $10 \%$ neem seed kernal extract caused the mortality of lady bird beetle, Adonia variegata by $73.3 \%$ compared with $65.0 \%$ mortality caused by $5.0 \%$ neem oil. [45] unveiled that when bees Apis millifera (adult workers) were subjected to the diet exposed to botanicals citronella oil, eucalyptus oil, garlic extract, neem oil, or rotenone, they suffered from $42 \%$ to $60 \%$ higher mortality rates compared with the uncontaminated food control. Andiroba oil showed no significant effect on adult workers' mortality. The higher mortality rates were also observed in worker larvae exposed to dietary andiroba oil, garlic extract and neem oil, but rotenone, citronella oil and eucalyptus oil had no significant effects on mortality rates of the worker larvae. When adult workers were raised from the larvae fed on a diet exposed to andiroba oil, garlic extract, and neem oil the survival rate decreased. During pupation and adult emergence, the mortality of larvae bee was induced by andiroba oil and garlic extracts [45]. [46] found that when subjected to aphids sprayed with the neem oil, the first instar larvae of Coccinella septempunctata experienced higher mortalities and the first instar larvae of Episyrphus balteatus were highly affected. Also, the hatching rates of Coccinella septempunctata and Chrysoperla carnea were highly affected. Despite their effectiveness in pest control, some botanical pesticides are lethal to beneficial insects. Thus, detailed knowledge of the lethal synthetic pesticides on beneficial insects is essential for sustainable control of insect pests and pollination activities for improved and sustainable agricultural production.

\subsection{Non Lethal (Indirect Effects)}

Non lethal effects of botanical pesticides may inhibit the ability of natural enemies to establish populations, suppress the capacity of natural enemies to utilize prey, reduce prey availability, affect parasitism or consumption rates; decrease reproduction, inhibit ability of natural enemies to recognize prey; influence the sex ratio (females:males), and reduce mobility, which could impact prey-finding [47]. Beneficial arthropods' activities will consequently be promoted if more knowledge will be provided in understanding the non lethal 
effects and the botanical pesticides that cause these effects.

\subsubsection{Reduced Parasitism Rates}

Azadirachtin and pyrethrum have been reported by [40] to seriously affect the development and behaviour of parasitoid Venturia canescens (Hymenoptera: Ichneumonidae). [48] studied the side effects of neem products on parasitism rates of Trichogramma pretiosum and Trichogramma minutum on Helicoverpa eggs. The authors found that NeemAzal-T/S reduced the parasitism rates to $50 \%, 48.9 \%, 71.1 \%$ and $73.3 \%$ at $2 \%, 1 \%, 0.5 \%, 0.25 \%$ concentrations, respectively compared to $96.6 \%$ on control experiment for $T$. pretiosum and NeemAzal PC, 05 reduced the parasitism rates to $70 \%, 67.8 \%, 70 \%$ and $80 \%$ on concentrations; $2 \%, 1 \%, 0.5 \%$ and $0.25 \%$ for $T$. Minutum. [42] reported that neem at $500 \mathrm{ppm}$ deterred the adult of $E$. formosa from ovipositing. Also when subjected to the whitefly nymphs treated with Pyrethrum, the adult $E$. formosa was discouraged from ovipositing on the treated nymphs and consequently low percentage of parasitised nymphs. The naphthoquinones also discouraged the parasitoids from ovipositing. [41] studied the effects of azadirachtin and pyrethrum and observed that the emergence rates of the egg-larval parasite Chelonus oculator were reduced when treated with azadirachtin at $\mathrm{LC}_{50}$ and $\mathrm{LC}_{25}$ values and pyrethrum at $\mathrm{LC}_{25}$ value (Table 2 and Table 3).

Establishing the relationship of the botanical pesticides with the parasitism rates is crucial in influencing the beneficial insects' activities in agricultural fields.

\subsubsection{Feeding and Stabbing Repellency of the Parasitoids and Pollinators}

[40] reported on repellent effects of oil of Azadirachta indica (Meliaceae) on the parasitoid Uscana lariophaga (Hymenoptera: Trichogrammatidae). [44] found that neem seed kernel extract (10\%) caused repellency in feeding by $72.0 \%$ of ladybird beetle, Adonia variegata while neem oil (5\%) caused a reduction in feeding by $68 \%$. The Delphastus pusillus, a predatory ladybird beetle avoided the eggs of whitefly, Bemisia tabaci for one day when subjected to the treatment of neem (Margosan-O). The feeding was resumed the next day [49]. [42] conducted studies on the stabbing behaviour of the parasitoid $E$. formosa and highlighted that when the host nymphs

Table 2. Sub lethal effects of azadirachtin on the development of egg-larval parasitoid Chelonus oculator.

\begin{tabular}{cccccc}
\hline Sex & Dose & $\begin{array}{c}\text { Development time } \\
\text { (day) }\end{array}$ & $\begin{array}{c}\text { Longevity } \\
\text { (day) }\end{array}$ & $\begin{array}{c}\text { Emergence ratio } \\
\text { Adult dry mass } \\
\text { (mg) }\end{array}$ & \begin{tabular}{c}
$1.65 \pm 0.002 \mathrm{~b}$ \\
\hline+
\end{tabular} \\
\hline $\mathrm{LC}_{25}$ & $27.23 \pm 0.26 \mathrm{~b}$ & $10.23 \pm 0.32 \mathrm{~b}$ & $40.43 \mathrm{~b}$ & $1.60 \pm 0.004 \mathrm{c}$ \\
& & & & $33.46 \mathrm{c}$ & $1.76 \pm 0.013 \mathrm{a}$ \\
& $\mathrm{LC}_{50}$ & $36.81 \pm 0.31 \mathrm{a}$ & $6.81 \pm 0.32 \mathrm{c}$ & $53.96 \mathrm{a}$ & $1.59 \pm 0.003 \mathrm{~b}$ \\
& $\mathrm{Control}$ & $21.30 \pm 0.33 \mathrm{c}$ & $18.56 \pm 0.37 \mathrm{a}$ & $40.43 \mathrm{~b}$ & $1.55 \pm 0.004 \mathrm{c}$ \\
& $\mathrm{LC}_{25}$ & $22.65 \pm 0.27 \mathrm{~b}$ & $5.91 \pm 0.23 \mathrm{~b}$ & $33.46 \mathrm{c}$ & $1.68 \pm 0.003 \mathrm{a}$ \\
\hline
\end{tabular}

Modified from [41].

Table 3. Sub lethal effects of pyrethrum on the development of egg-larval parasitoid Chelonus oculator.

\begin{tabular}{|c|c|c|c|c|c|}
\hline Sex & Dose & $\begin{array}{c}\text { Development time } \\
\text { (day) }\end{array}$ & $\begin{array}{l}\text { Longevity } \\
\text { (day) }\end{array}$ & Emergence ratio & $\begin{array}{c}\text { Adult dry mass } \\
\text { (mg) }\end{array}$ \\
\hline \multirow[t]{3}{*}{ q } & $\mathrm{LC}_{25}$ & $35.08 \pm 0.41 a$ & $8.00 \pm 0.27 b$ & 33.30b & $1.61 \pm 0.004 b$ \\
\hline & $\mathrm{LC}_{50}$ & - & & - & - \\
\hline & Control & $21.30 \pm 0.33 b$ & $18.56 \pm 0.37 a$ & 53.96a & $1.76 \pm 0.013 \mathrm{a}$ \\
\hline \multirow[t]{3}{*}{$\hat{\sigma}$} & $\mathrm{LC}_{25}$ & $28.88 \pm 0.37 a$ & $4.11 \pm 0.26 b$ & 33.30b & $1.53 \pm 0.004 b$ \\
\hline & $\mathrm{LC}_{50}$ & - & & - & - \\
\hline & Control & $18.70 \pm 0.30 b$ & $13.63 \pm 0.30 a$ & 53.96a & $1.68 \pm 0.003 \mathrm{~b}$ \\
\hline
\end{tabular}

Modified from [41]. 
(Trialeurodes vaporariorum) were subjected to the treatments of naphthoquinones and pyrethrum extracts, the botanical insecticides discouraged the adult E. formosa from stabbing into treated nymphs. Also the sublethal doses of neonicotinyl insecticide starting around $10 \mathrm{ppb}$ caused bees to lose navigation and foraging skills. It is therefore of great importance to investigate more botanical pesticides that cause stabbing and feeding repellency on beneficial insects and the ways beneficial arthropods are affected from the botanicals. This will allow for optimized and sustainable use of botanical pesticides while avoiding or minimizing side effects on beneficial insects.

\subsubsection{Parasitoid, Predators and Pollinators' Developmental Impairment}

[48] and [40] reported on sublethal effect of botanical pesticides on predators, parasitoids. [22] showed that the malformation in development of the natural enemies caused by these botanical pesticides may result into decrease in their parasitism and predation efficiency. [4] unveiled the disorder in internal organs of the larvae and adults of the predator Mallada signatus (Neuroptera: Chrysopidae) after being exposed to sublethal doses of botanical insecticides with azadirachtin. The study on the effects of azadirachtin and pyrethrum on the development of the parasitoid Venturia canescens (Hymenoptera: Ichneumonidae) by [40] showed that sublethal doses of azadirachtin prolonged the development time of $V$. canescens from parasitized Ephestia larvae, third and fifth instar. The emergence rates of $V$. canescens from parasitized Ephestia larvae when treated with azadirachtin were reduced compared with the control. The adult longevity and dry mass were also significantly reduced compared with the control. [45] showed that the body masses of honey bees (A. millifera) decreased for the adults that emerged from larvae fed on a diet exposed to andiroba oil, citronella oil, garlic extract, neem oil and rotenone. [41] reported on the decrease in body mass and longevity whilst prolonging development time of the Braconidae, Chelonus oculator when subjected to azadirachtin at $\mathrm{LC}_{50}$ and $\mathrm{LC}_{25}$ values and pyrethrum at $\mathrm{LC} 25$ value (Table 2 and Table 3). The limited understanding of the developmental impairment of botanical pesticides on parasitoids, predators and pollinators calls for further study to improve pollination and natural pest management services provided by these beneficial arthropods’ populations in and around agricultural fields.

\section{Recommendations for Further Studies and Conclusions}

Botanical and synthetic pesticides generate acute toxicity and sub-lethal effects on beneficial insects responsible for natural pest control and pollination. The detrimental effects caused by synthetic pesticides have long been reported and several strategies are in place including biological pest control. The negative effects posed by botanicals however, are of more concern as this might limit the effectiveness of biological pest control strategies. Botanicals are often categorized as safe and environmentally friendly but their use for insect pests control should always be done with caution. Evaluation of the potential risks of the pesticides to non-target organisms is crucial in optimizing ecosystem services (e.g. natural pest control or pollination) and consequently better agricultural yields. More research is therefore needed to determine the side effects of both botanical and synthetic pesticides on predators, parasitoids and pollinators. Most of the detrimental effects especially of the botanicals are based on dosage which suggests for more research on the right dosage. It is also important that beneficial insects in a particular field environment are studied before investing on a particular pesticide use to allow for precautions as to which specific chemical and dosage to use.

\section{References}

[1] Ngowi, A.V.F., Mbise, T.J., Ijani, A.S.M., London, L. and Ajayi, O.C. (2007) Smallholder Vegetable Farmers in Northern Tanzania: Pesticides Use Practices, Perceptions, Cost and Health Effects. Crop Protection, 26, 1617-1624. http://dx.doi.org/10.1016/j.cropro.2007.01.008

[2] Desneux, N., Decourtye, A. and Delpuech, J.-M. (2007) The Sublethal Effects of Pesticides on Beneficial Arthropods. Annual Review of Entomology, 52, 81-106. http://dx.doi.org/10.1146/annurev.ento.52.110405.091440

[3] Coats, J.R. (2012) Insecticide Mode of Action. Academic Press.

[4] Qi, B., Gordon, G. and Gimme, W. (2001) Effects of Neem-Fed Prey on the Predacious Insects Harmonia conformis (Boisduval) (Coleoptera: Coccinellidae) and Mallada signatus (Schneider) (Neuroptera: Chrysopidae). Biological Control, 22, 185-190. http://dx.doi.org/10.1006/bcon.2001.0965

[5] Sharma, H.C., War, A.R. and Sahrawat, K.L. (2012) Botanical Pesticides: Environmental Impact. In: Environmental Safety of Biotech and Conventional IPM Technologies, Studium Press LLC, Texas, 159-190. 
[6] Lebuhn, G., Droege, S., Connor, E.F., Gemmill-Herren, B., Potts, S.G., Minckley, R.L. and Roubik, D.W. (2013) Detecting Insect Pollinator Declines on Regional and Global Scales. Conservation Biology, 27, 113-120. http://dx.doi.org/10.1111/j.1523-1739.2012.01962.x

[7] Isman, M. (2013) Botanical Insecticides in Modern Agriculture and an Increasingly Regulated World Conference at National Center for Animal and Plant Health (CENSA). Mayabeque, Cuba, 51.

[8] Zacharia, J.T. (2011) Ecological Effects of Pesticides. INTECH Open Access Publisher.

[9] McMichael, A.J. (2003) Global Climate Change and Health: An Old Story Writ Large. Climate Change and Human Health: Risks and Responses. World Health Organization, Geneva.

[10] FAOSTAT, F.B.S. (2005) Food and Agriculture Organization. http://faostat.fao.org/faostat

[11] Gill, H.K. and Garg, H. (2014) Pesticide: Environmental Impacts and Management Strategies. Pesticides-Toxic Effects. Intech. Rijeka, Croatia, 187-230.

[12] Bacci, L., Crespo, A.L., Galvan, T.L., Pereira, E.J., Picanço, M.C., Silva, G.A. and Chediak, M. (2007) Toxicity of Insecticides to the Sweetpotato Whitefly (Hemiptera: Aleyrodidae) and Its Natural Enemies. Pest Management Science, 63, 699-706. http://dx.doi.org/10.1002/ps.1393

[13] Thomson, L., Glenn, D. and Hoffmann, A. (2001) Effects of Sulfur on Trichogramma Egg Parasitoids in Vineyards: Measuring Toxic Effects and Establishing Release Windows. Animal Production Science, 40, 1165-1171. http://dx.doi.org/10.1071/EA00074

[14] Shoeb, M.A. (2010) Effect of Some Insecticides on the Immature Stages of the Egg Para-Sitoid Trichogramma evanescens. Egyptian Academic Journal of Biological Sciences, 3, 31-38.

[15] Mollah, M.I., Rahman, M. and Alam, Z. (2013) Effect of Insecticides on Lady Bird Beetle (Coleoptera: Coccinellidae) in Country Bean Field. Middle-East Journal of Scientific Research, 17, 1607-1610.

[16] Islam, A.T.M.F. and Sardar, M.A. (1997) Toxic Effects of Insecticides on Bean Aphid, Aphis craccivora (Koch), and Its Predator Menochilus sexmaculatus (F.) (Coleoptera: Coccinellidae). Bangladesh Journal of Entomology, 7, 13-19.

[17] Martinou, A., Seraphides, N. and Stavrinides, M. (2014) Lethal and Behavioral Effects of Pesticides on the Insect Predator Macrolophus pygmaeus. Chemosphere, 96, 167-173. http://dx.doi.org/10.1016/j.chemosphere.2013.10.024

[18] Sclar, D.C., Gerace, D. and Cranshaw, W.S. (1998) Observations of Population Increases and Injury by Spider Mites (Acari: Tetranychidae) on Ornamental Plants Treated with Imidacloprid. Journal of Economic Entomology, 91, 250255. http://dx.doi.org/10.1093/jee/91.1.250

[19] Krischik, V. (2014) Protecting Bees and Beneficial Insects from Systemic Insecticides Applied in Landscapes. University of Minnesota Extension, Minneapolis.

[20] Bloomquist, J.R. (2009) Insecticides: Chemistries and Characteristics. From Radcliffe’s IPM World Textbook, University of Minnesota, Minneapolis. http://ipmworld.umn.edu/chapters/bloomq.htm

[21] Dent, D. (2000) Insect Pest Management. CABI. http://dx.doi.org/10.1079/9780851993409.0000

[22] Fernandes, F.L., Bacci, L. and Fernandes, M.S. (2010) Impact and Selectivity of Insecticides to Predators and Parasitoids. Entomo Brasilis, 3, 1-10. http://dx.doi.org/10.12741/ebrasilis.v3i1.52

[23] Cortesero, A., Stapel, J. and Lewis, W. (2000) Understanding and Manipulating Plant Attributes to Enhance Biological Control. Biological Control, 17, 35-49. http://dx.doi.org/10.1006/bcon.1999.0777

[24] Rice, P.J., Rice, P.J., Arthur, E.L. and Barefoot, A.C. (2007) Advances in Pesticide Environmental Fate and Exposure Assessments. Journal of Agricultural and Food Chemistry, 55, 5367-5376. http://dx.doi.org/10.1021/jf063764s

[25] Schmuck, R. (1999) No Causal Relationship between Gaucho® Seed Dressing in Sunflowers and the French Bee Syndrome. Pflanzenschutz Nachrichten-Bayer (English Edition), 52, 257-299.

[26] Umoru, P., Powell, W. and Clark, S. (1996) Effect of Pirimicarb on the Foraging Behaviour of Diaeretiella Rapae (Hymenoptera: Braconidae) on Host-Free and Infested Oilseed Rape Plants. Bulletin of Entomological Research, 86, 193201. http://dx.doi.org/10.1017/S0007485300052445

[27] Chitgar, M.G. and Ghadamyari, M. (2012) Effects of Amitraz on the Parasitoid Encarsia formosa (Gahan) (Hymenoptera: Aphelinidae) for Control of Trialeurodes vaporariorum Westwood (Homoptera: Aleyrodidae): IOBC Methods. Journal of the Entomological Research Society, 14, 61-69.

[28] Bernard, M.B., Horne, P.A. and Hoffmann, A.A. (2005) Eriophyoid Mite Damage in Vitis vinifera (Grapevine) in Australia: Calepitrimerus vitis and Colomerus vitis (Acari: Eriophyidae) as the Common Cause of the Widespread "Restricted Spring Growth” Syndrome. Experimental \& Applied Acarology, 35, 83-109. http://dx.doi.org/10.1007/s10493-004-1986-4

[29] Liu, T.-X. and Chen, T.-Y. (2001) Effects of the Insect Growth Regulator Fenoxycarb on Immature Chrysoperla rufilabris (Neuroptera: Chrysopidae). Florida Entomologist, 84, 628-633. http://dx.doi.org/10.2307/3496394 
[30] Radjabi, G. (1995) Investigations on the Various Aspects of Hymenopterous Egg Parasitoids in Alleviating the Outbreak Occurrence of Eurygaster integriceps in Iran. Applied Entomology and Phytopathology, 62, 13-14.

[31] Saber, M., Hejazi, M.J., Kamali, K. and Moharramipour, S. (2005) Lethal and Sublethal Effects of Fenitrothion and Deltamethrin Residues on the Egg Parasitoid Trissolcus grandis (Hymenoptera: Scelionidae). Journal of Economic Entomology, 98, 35-40. http://dx.doi.org/10.1603/0022-0493-98.1.35

[32] Araya, J.E., Araya, M. and Guerrero, M.A. (2010) Effects of Some Insecticides Applied in Sublethal Concentrations on the Survival and Longevity of Aphidius ervi (Haliday) (Hymenoptera: Aphidiidae) Adults. Chilean Journal of Agricultural Research, 70, 221-227. http://dx.doi.org/10.4067/s0718-58392010000200005

[33] Yang, E., Chuang, Y., Chen, Y. and Chang, L. (2008) Abnormal Foraging Behavior Induced by Sublethal Dosage of Imidacloprid in the Honey Bee (Hymenoptera: Apidae). Journal of Economic Entomology, 101, 1743-1748. http://dx.doi.org/10.1603/0022-0493-101.6.1743

[34] Morandin, L.A. and Winston, M.L. (2003) Effects of Novel Pesticides on Bumble Bee (Hymenoptera: Apidae) Colony Health and Foraging Ability. Environmental Entomology, 32, 555-563. http://dx.doi.org/10.1603/0046-225X-32.3.555

[35] Delpuech, J.M., Gareau, E.O.T. and Fouillet, P. (1998) Sublethal Impact and Selectivity of Insecticides to Predators and Parasitoids. Chemosphere, 36, 1775-1785.

[36] Thomson, L. (2012) Pesticide Impacts on Beneficial Species. Australian Government Grape and Wine Research and Development Corp., Factsheet May 2012, 1-7.

[37] Medina, P., Budia, F., González, M., Rodríguez, B., Díaz, A., Huerta, A. and Viñuela, E. (2006) Effects of Botanical Insecticides on Two Natural Enemies of Importance in Spain: Chrysoperla carnea (Stephens) and Psyttalia concolor (Szépligeti). IOBC WPRS Bulletin, 29, 85-93.

[38] Schneider, M., Smagghe, G., Pineda, S. and Vinuela, E. (2004) Action of Insect Growth Regulator Insecticides and Spinosad on Life History Parameters and Absorption in Third-Instar Larvae of the Endoparasitoid Hyposoter didymator. Biological Control, 31, 189-198. http://dx.doi.org/10.1016/j.biocontrol.2004.04.013

[39] Maia, M.F. and Moore, S.J. (2011) Plant-Based Insect Repellents: A Review of Their Efficacy, Development and Testing. Malaria Journal, 10, S11. http://dx.doi.org/10.1186/1475-2875-10-s1-s11

[40] Tunca, H., Kilinçer, N. and Özkan, C. (2012) Side-Effects of Some Botanical Insecticides and Extracts on the Parasitoid, Venturia canescens (Grav.) (Hymenoptera: Ichneumonidae). Turkish Journal of Entomology, 36, 205-214.

[41] Tunca, H., Kilinçer, N. and Özkan, C. (2014) Toxicity and Repellent Effects of Some Botanical Insecticides on the Egg-Larval Parasitoid Chelonus oculator Panzer (Hymenoptera: Braconidae). Scientific Research and Essays, 9, 106113. http://dx.doi.org/10.5897/SRE2014.5823

[42] Simmonds, M., Manlove, J., Blaney, W. and Khambay, B. (2002) Effects of Selected Botanical Insecticides on the Behaviour and Mortality of the Glasshouse Whitefly Trialeurodes vaporariorum and the Parasitoid Encarsia formosa. Entomologia Experimentalis et Applicata, 102, 39-47. http://dx.doi.org/10.1046/j.1570-7458.2002.00923.x

[43] Bonsignore, C. and Vacante, V. (2012) Influences of Botanical Pesticides and Biological Agents on Orius laevigatusFrankliniella occidentalis Dynamics under Greenhouse Conditions. Journal of Plant Protection Research, 52, 15-23. http://dx.doi.org/10.2478/v10045-012-0003-x

[44] Swaminathan, R., Jat, H. and Hussain, T. (2010) Side Effects of a Few Botanicals on the Aphidophagous Coccinellids. Journal of Biopesticides, 3, 81-84.

[45] Xavier, V.M., Picanço, M.C., Chediak, M., Júnior, P.A.S., Ramos, R.S. and Martins, J.C. (2015) Acute Toxicity and Sublethal Effects of Botanical Insecticides to Honey Bees. Journal of Insect Science, 15, 137. http://dx.doi.org/10.1093/jisesa/iev110

[46] Ahmad, M., Ossiewatsch, H.R. and Basedow, T. (2003) Effects of Neem-Treated Aphids as Food/Hosts on Their Predators and Parasitoids. Journal of Applied Entomology, 127, 458-464. http://dx.doi.org/10.1046/j.0931-2048.2003.00779.x

[47] Van de Veire, M. and Tirry, L. (2003) Side Effects of Pesticides on Four Species of Beneficials Used in IPM in Glasshouse Vegetable Crops: "Worst Case” Laboratory Tests. IOBC WPRS Bulletin, 26, 41-50.

[48] El-Wakeil, N., Gaafar, N. and Vidal, S. (2006) Side Effect of Some Neem Products on Natural Enemies of Helicoverpa (Trichogramma spp.) and Chrysoperla carnea. Archives of Phytopathology and Plant Protection, 39, 445-455. http://dx.doi.org/10.1080/03235400500356160

[49] Hoelmer, K., Osborne, L. and Yokomi, R. (1990) Effects of Neem Extracts on Beneficial Insects in Greenhouse Culture. ARS US Department of Agriculture, Agricultural Research Service Aphidophagous Coccinellids. Journal of Biopesticides, 3, 81-84. 